\title{
Regorafenib - Five Years in Review
}

\author{
Rodrigo Moisés de Almeida Leite, ${ }^{1}$ Isabela Demarchi and Taís Rondello Bonatti ${ }^{3}$ \\ 1. Faculty of Medicine of Jundiai, Jundiaí, Brazil; 2. Nove de Julho University, São Paulo, Brazil; 3. Paulista University, Campinas, Brazil
}

DOl: https://doi.org/10.17925/EOH.2020.16.1.24

$\mathrm{R}$ egorafenib, a drug approved in 2013, is a multikinase inhibitor that targets angiogenic, stromal and oncogenic tyrosine kinase receptors, Current labelled indications include colorectal cancer, hepatocellular carcinoma and gastrointestinal stromal tumours. Recent studies have shown that regorafenib significantly improves survival of patients with glioblastoma, osteosarcoma and gastric adenocarcinoma. It presents a tolerable profile of side effects, comprising hand-foot syndrome, fatigue, diarrhoea, hypertension, thrombocytopaenia and anaemia. Some side effects, notably hand-foot syndrome and hypothyroidism, are independent predictors of better outcome. Side-effect severity is different between patients, possibly related to prior exposure to tyrosine kinase inhibitors. Synergic effect with immune checkpoint inhibitors has been described in some clinical trials, which may be related to the reduction of tumour-associated macrophages, a mechanism of resistance promoted by tumours. Ongoing clinical trials are testing regorafenib in distinct cancers, including soft-tissue sarcomas.

\section{Keywords}

Regorafenib, vascular endothelial growth factors, Ras, $B R A F$, colorectal cancer, hepatocellular carcinoma, gastrointestinal stromal tumour, glioblastomas, hand-foot syndrome, nivolumab, gastric cancer, osteosarcoma, hypothyroidism, soft tissue sarcoma

Disclosures: Rodrigo Moisés de Almeida Leite, Isabela Demarchi and Taís Rondello Bonatti have no financial or non-financial relationships or activities to declare in relation to this article.

Review Process: Double-blind peer review.

Compliance with Ethics: This article involves a review of literature and does not report on new clinical data, or any studies with human or animal subjects performed by any of the authors.

Authorship: All named authors meet the International Committee of Medical Journal Editors (ICMJE) criteria

for authorship of this manuscript, take responsibility for the integrity of the work as a whole and have given final approval for the version to be published. Access: This article is freely accessible at touchONCOLOGY.com. (c) Touch Medical Media 2020.

Received: 4 November 2019

Accepted: 13 January 2020

Published Online: 28 February 2020

Citation: European Oncology \& Haematology.

2020;16(1):24-8

Corresponding Author: Rodrigo Moisés de Almeida Leite, Rua Francisco Telles 250, Jundiaí São Paulo, CEP 13202-550, Brazil. E: rodrigomoises@me.com

Support: No funding was received in the publication of this article.
Regorafenib was approved as a third-line treatment for colorectal cancer in 2013. Notwithstanding its promising pharmacodynamics, 5 years after its introduction only a small subgroup of patients has benefitted from this drug; and of those, the treatment effects were surprisingly restricted.' Regorafenib is an oral multikinase inhibitor against vascular endothelial growth factor receptor 1 (VEGFR-1), VEGFR3, VEGFR1/3, platelet-derived growth factor receptors subunit beta (PDGFR- $\beta$ ), fibroblast growth factor receptor 1 (FGFR1), TIE-2C-KIT, RET/Raf1 and protein kinase B-Raf (BRAF); it has three targets: angiogenesis, oncogenesis and proliferations. ${ }^{2}$

The convenience of the administration route, plus its multitasking mechanism of action, could promise a new age in the treatment of many types of cancer. ${ }^{3}$ Also, regorafenib presents a tolerable set of side effects compared with current cytotoxic and antiangiogenic therapies. Apart from the approval of regorafenib in advanced and inoperable gastrointestinal stromal tumours (GISTS), and the recent approval for its use in the treatment of hepatocellular carcinoma (HCC) progressing after sorafenib treatment, the scope of prescriptions for regorafenib has remained disappointingly limited. ${ }^{4}$ All the approved treatments for regorafenib have one characteristic in common: it is always the last-line agent, and it is only effective in patients who have failed previous therapies. ${ }^{.}$This subgroup of patients restricts the current usage of regorafenib in a triplet of highly lethal diseases, in highly advanced cases, and in short-survival patients, who usually have other diseases. Some attempts have been made with regorafenib in earlier-stage cancer, but with negative results, to date. ${ }^{6}$

Another aspect of regorafenib is its cost-benefit profile. At present, it presents a high cost with very little or no benefit for patients, thus presenting an unfavourable cost-benefit ratio. ${ }^{1}$ As for the future, regorafenib may present a positive synergic administration with checkpoint inhibitors, as has been associated with bevacizumab.?

The aim of this review is to present the current and possible future usages of regorafenib, summarising the pharmacodynamic targets of this drug, and to pave way for new clinical trials that may benefit more patients at an acceptable cost-benefit ratio.

The literature review was conducted in the following steps: identification theme and formulation of the research, construction of an instrument for collecting relevant data from the articles found, evaluation and analysis of selected articles, and interpretation of results obtained. The searches were performed on the following bases of bibliographic data: PubMed, ScienceDirect and Scopus. The search criteria used were clinical phase I, II or III clinical trials; case reports; retrospective studies; and reviews in basic sciences published between 1992 and 2019, available in English, and addressed the theme of the drug regorafenib. Sixty articles met the criteria drawn by the authors and were therefore included in the review. 


\section{Review of drug recipients for regorafenib} Vascular endothelial growth factors

VEGFs comprise a polypeptide family with multiple functions involved in angiogenesis, lymphangiogenesis and increased capillary permeability acting on specific receptors on cell surfaces. ${ }^{8,9}$ The VEGF family consists of five members (VEGF-A, VEGF-B, VEGF-C, VEGF-D and VEGF-E) that have their functions mediated by the tyrosine kinase receptors (RTK) VEGFR-1, VEGFR-2 and VEGFR-3.9,10 Intracellular phosphorylation initiates a cascade of cytoplasmic reactions that culminates in several cellular responses related to migration and proliferation of endothelial cells, as well as fenestration and permeabilisation of the vessel. ${ }^{11-14}$

VEGFR-1 is an RTK that plays a role in physiological and pathological angiogenesis in the context of receptor dimerisation and an interaction with its ligands. ${ }^{15}$ The VEGFR-1 receptor, found in the endothelial-cell membrane, when binding to the VEGF-A ligand, promotes cell migration, blood vessel organisation and gene expression of monocytes and macrophages. ${ }^{16}$ VEGFR-3 is an RTK expressed on all endothelial cells during early embryogenesis. During later developmental stages, the expression of VEGFR-3 is restricted to lymphatic vessels. ${ }^{17.18}$ VEGFR-3 is therefore involved in the remodelling of primary capitis vasculature, embryonic cardiovascular development, and regulation of growth and maintenance of the Iymphatic system. ${ }^{18,19}$ Embryonic defects related to the VEGFR-3 gene during the stage of development of vasculogenesis, leads to the formation of abnormal budding, organisation and vascular remodelling. ${ }^{18}$

VEGF-A (also known as vascular permeability factor) was originally purified based on its mitogenic activity towards endothelial cells, and on its ability to induce microvascular permeability. ${ }^{19}$ VEGF-B has angiogenic properties and may be involved in cell adhesion and migration and in the regulation of extracellular matrix degradation. VEGF-B is expressed primarily in cardiac and skeletal muscle tissues of the embryo and adults. ${ }^{10}$ VEGF-C was identified as a growth factor for the lymphatic vascular system. During embryogenesis, VEGF-C is expressed in a complex spatial and temporal pattern, and its expression persists in the heart, lung and skeletal muscles in adults. VEGF-D stimulates mitogenic responses in endothelial cells. ${ }^{19}$

\section{Mitogen-activated protein kinase pathway}

The mitogen-activated protein kinase (MAPK) pathway leads to cell proliferation, differentiation, migration, survival and angiogenesis. ${ }^{20}$ This pathway is composed of the small guanidine triphosphatase (GTPase), which activates the Raf family proteins..$^{21,22}$ Ras, a small GTP-binding protein, is an important component of the signal transduction pathway used by growth factors to initiate cell growth and differentiation. Cellular activation with growth factors, such as epidermal growth factor (EGF), induces Ras to move from an inactive state linked to GDP to an active state linked to GTP. ${ }^{21}$

Recently, a combination of genetic and biochemical studies has resulted in the elucidation of a signalling pathway leading from growth factor receptors to Ras. Following EGF binding, the EGF tyrosine kinase receptor is activated, leading to autophosphorylation of the receptor in multiple tyrosine residues. ${ }^{21,23,24}$

\section{BRAF}

BRAF is a serine/threonine protein kinase, encoded on chromosome 7q34, which activates the MAPK/extracellular signal-regulated kinase (ERK) signalling pathway. BRAF is the family member most easily activated by Ras. ${ }^{25,26}$ In addition, BRAF basal kinase activity is higher than that of other family members. ${ }^{27,28}$ This provides a potential reason for the frequent mutational activation of BRAF seen in human tumours. ${ }^{29}$
Table 1: Regorafenib pharmacodynamic targets

\begin{tabular}{|l|l|l|}
\hline \multirow{2}{*}{ Receptor family } & Receptor subunit & Physiological actions \\
\hline & VEGFR-1 & Angiogenesis \\
\cline { 2 - 3 } & VEGFR-3 & Maintenance of lymphatic system \\
\cline { 2 - 3 } & VEGF-A & Microvascular permeability \\
\cline { 2 - 3 } & VEGF-B & $\begin{array}{l}\text { Angiogenesis, cell adhesion, } \\
\text { cell migration, extracellular matrix } \\
\text { degradation }\end{array}$ \\
\cline { 2 - 3 } & VEGF-C & Growth factor for lymphatic system \\
\cline { 2 - 3 } & VEGF-D & $\begin{array}{l}\text { Mitogenesis responses of } \\
\text { endothelial cells }\end{array}$ \\
\hline Serine protein \\
kinases & BRAF & $\begin{array}{l}\text { Genomic instability, cancer cells } \\
\text { proliferation, upstream growth } \\
\text { stimuli }\end{array}$ \\
\hline \multirow{2}{*}{$\begin{array}{l}\text { Mitogen-activated } \\
\text { protein kinases }\end{array}$} & Raf family proteins & $\begin{array}{l}\text { Cellular proliferation, cellular } \\
\text { migration, apoptosis inhibition }\end{array}$ \\
\cline { 2 - 3 } & Ras family proteins & Angiogenesis \\
\hline
\end{tabular}

$B R A F=$ serine/threonine-protein kinase $B-R a f ;$ VEGF = vascular endothelial growth factor; VEGFR = vascular endothelial growth factor receptor.

Raf kinases can homo- and heterodimerise, $, 30,31$ and the structure of an active Raf kinase is that of a side-by-side dimer in which only one partner should have catalytic activity. ${ }^{32}$ Dimerisation is improved by Ras $^{33}$ and is subject to negative feedback regulation by ERK. ${ }^{31,34}$ Several Raf mutations have been implicated in the induction of genomic instability, boosting the proliferation of cancer cells more frequently in melanoma. For example, BRAF signals mutated as a monomer, independent of upstream growth stimuli. A more frequent BRAF mutation, BRAFV600E, provokes constitutive kinase, as well as insensitivity to negative feedback mechanisms. ${ }^{29,35}$ Table 1 summarises drug targets for regorafenib.

\section{Current approved uses of regorafenib}

As of 2018, regorafenib was approved by the US Food and Drug Administration (FDA) for three specific clinical settings. The first approval of this tyrosine kinase inhibitor was for colorectal cancer and, in this scenario, after progression of standard adjuvant treatment in metastatic disease. It is advocated that treatment continues until disease progression or unacceptable toxicity levels have been reached, which in some cases, as demonstrated in a recent Japanese case-report, may take several years. ${ }^{36}$ Subsequently, approval was granted for management of GIST. Also, approval is almost prohibitively narrow, as it comprises a tumour that is either locally advanced, unresectable or metastatic after treatment with imatinib and sunitinib. ${ }^{36,37}$

Most recently, attention has been drawn to HCC. Similarly, to the two prior approvals, in this case, the scope of the drug is for patients who are candidates for systemic treatment as a second-line treatment after failure or intolerance for sorafenib. In this scenario, it is yet unclear whether regorafenib or the immune checkpoint inhibitor nivolumab is the most beneficial line of therapy. ${ }^{37}$ Dosages and indications are summarised in Table 2.38,39

\section{Possible complications of therapy with regorafenib}

As is germane to every antineoplastic treatment currently available, the profile of side effects is crucial to patient adherence, completion of therapy and therapeutic success. In the particular case of regorafenib, notwithstanding the convenience of its oral presentation, serious side effects may occur, and make the continuation of therapy unadvisable. 
Table 2: Indications, dosage and duration of regorafenib treatment under current approved uses

\begin{tabular}{|c|c|c|c|}
\hline Cancer type & Indications & Dosage & Duration of treatment \\
\hline Colorectal cancer & $\begin{array}{l}\text { - Colorectal cancer that is metastatic } \\
\text { - Progression after treatment with all } \\
\text { lines of therapy }\end{array}$ & $\begin{array}{l}\text { - Start with } 80 \text { mg daily (two pills of } \\
40 \text { mg) and escalate weekly until goal } \\
\text { of } 160 \text { mg daily }\end{array}$ & $\begin{array}{l}\text { - One cycle of treatment: } 21 \text { days of therapy } \\
\text { and a 7-day pause } \\
\text { - Continue until disease progression } \\
\text { and/or toxicity } \\
\text { - A case report from Japan demonstrates } \\
\text { advanced metastatic stable disease after } \\
2 \text { years of treatment }{ }^{36}\end{array}$ \\
\hline $\begin{array}{l}\text { Gastrointestinal } \\
\text { stromal tumour }\end{array}$ & $\begin{array}{l}\text { - Metastatic or unresectable } \\
\text { gastrointestinal stromal tumour that is } \\
\text { no longer responsive to imatinib and } \\
\text { sunitinib }\end{array}$ & $\begin{array}{l}\text { - } \text { Currently, there is no evidence to } \\
\text { support a lower initial dose } \\
\text { - } 160 \mathrm{mg} \text { (four pills of } 40 \mathrm{mg} \text { ) daily }\end{array}$ & $\begin{array}{l}\text { - One cycle of treatment: } 21 \text { days of therapy } \\
\text { and a 7-day pause } \\
\text { - continue until disease progression } \\
\text { and/or toxicity }\end{array}$ \\
\hline $\begin{array}{l}\text { Hepatocellular } \\
\text { carcinoma }\end{array}$ & $\begin{array}{l}\text { - Second-line of systemic treatment after } \\
\text { failure of sorafenib }\end{array}$ & $\begin{array}{l}\text { - } \text { Currently, there is no evidence to } \\
\text { support a lower initial dose } \\
\text { - } 160 \mathrm{mg} \text { (four pills of } 40 \mathrm{mg} \text { ) daily }\end{array}$ & $\begin{array}{l}\text { - One cycle of treatment: } 21 \text { days of therapy } \\
\text { and a 7-day pause } \\
\text { - continue until disease progression } \\
\text { and/or toxicity }\end{array}$ \\
\hline
\end{tabular}

Most patients will present with grade three or four adverse effects. According to the current evidence, the most frequent side effects are hand-foot syndrome, fatigue, diarrhoea, hypertension, thrombocytopaenia and anaemia. ${ }^{3}$

Interestingly, hand-foot syndrome has been reported, by some clinical trials, to be related with a better outcome. Although it is still early to conclude the causes or the magnitude of this relation, this piece of information may become a tool to predict outcomes of the treatment in the future. ${ }^{3}$ Also, hypothyroidism has been shown to be an independent predictor of improved overall survival in patients with colorectal cancer. A prospective study in Korea has demonstrated clinical hypothyroidism as a statistically significant protective factor for overall survival (hazard ratio 0.35; $\mathrm{p}=0.007$ ). ${ }^{40} \mathrm{~A}$ study in Italy has drawn similar conclusions. ${ }^{41}$ Other side effects have been associated with improved progression-free survival in regorafenib monotherapy for advanced colorectal cancer. The TRIBUTE analysis was a retrospective study of 144 patients, which demonstrated improved progression-free survival in the subsets of patients who developed skin rash, hypertension, diarrhea and hypothyroidism. ${ }^{42}$

Of note, severity of side effects differs between types of cancer. ${ }^{43}$ Treatment of metastatic colorectal cancer is related with more severe side effects than GIST and HCC. This might be related to the timing of therapy. Regorafenib therapy for GIST and HCC is approved after failure of other tyrosine kinases inhibitors, which means that patients have already been exposed to this class of drug, lessening potential side effects. The most important side effects are summarised in Table 3.

\section{Survival benefit with regorafenib}

Regorafenib shows a survival benefit in a variety of cancers. ${ }^{38,39}$ Regarding the labelled indications, patients with metastatic colorectal cancer and advanced HCC may benefit from modest increases in overall survival. As for GISTS, in spite of increase in progression-free survival, regorafenib has failed to improve overall survival. ${ }^{44}$ The latter may be due to the design of the study, allowing patients to crossover between the two arms of the trial. Similarly, it has been associated with prolonged progression-free survival in osteosarcoma, ${ }^{45,46}$ with no benefit in overall survival. Survival benefits with regorafenib compared to prior standard/current recommended care are summarised in Figure 1.
Table 3: Organs and/or systems affected by adverse effects of regorafenib and management

\begin{tabular}{|c|c|c|}
\hline Organ or system & Adverse effects & Management \\
\hline \multirow[t]{3}{*}{ Dermatologic } & Hand-foot syndrome & \multirow[t]{3}{*}{ Topical steroids, reduction of dose } \\
\hline & Rash & \\
\hline & Desquamation & \\
\hline \multirow[t]{2}{*}{ Cardiovascular } & Hypertension & $\begin{array}{l}\text { - Avoid diuretics, as they may } \\
\text { worsen dehydration cause } \\
\text { by diarrhoea } \\
\text { - ACE inhibitors, ARBs, CCBs } \\
\text { can be safely used } \\
\text { - If not controlled with } \\
\text { medication, discontinue } \\
\text { regorafenib }\end{array}$ \\
\hline & Haemorrhage & $\begin{array}{l}\text { Hold treatment until cessation } \\
\text { of haemorrhage }\end{array}$ \\
\hline \multirow[t]{3}{*}{ Gastrointestinal } & Stomatitis & $\begin{array}{l}\text { Frequent rinsing with } \\
\text { saline nystatin }\end{array}$ \\
\hline & Diarrhoea & $\begin{array}{l}\text { Short course loperamide, } \\
\text { rehydration with electrolytes }\end{array}$ \\
\hline & $\begin{array}{l}\text { Abnormalities in liver } \\
\text { function }\end{array}$ & $\begin{array}{l}\text { Generally occurs in the first } \\
\text { treatment cycles. Depending on } \\
\text { the abnormalities, it is possible } \\
\text { to observe, reduce the dose or } \\
\text { permanently discontinue }\end{array}$ \\
\hline Genitourinary & Proteinuria & $\begin{array}{l}\text { Dose reduction or permanent } \\
\text { discontinuation }\end{array}$ \\
\hline \multirow[t]{4}{*}{ Metabolic } & Hypophosphataemia & \multirow{4}{*}{$\begin{array}{l}\text { Clinic support, dose reduction, } \\
\text { permanent discontinuation }\end{array}$} \\
\hline & Hypocalcaemia & \\
\hline & Hypokalaemia & \\
\hline & Hyponatraemia & \\
\hline Endocrinological & Hypothyroidism & $\begin{array}{l}\text { Thyroid function monitoring, } \\
\text { T4 reposition }\end{array}$ \\
\hline \multirow[t]{2}{*}{ Haematologic } & Anaemia & \multirow{2}{*}{$\begin{array}{l}\text { Dose reduction or permanent } \\
\text { discontinuation }\end{array}$} \\
\hline & Thrombocytopaenia & \\
\hline
\end{tabular}

$A C E=$ angiotensin-converting enzyme; $A R B=$ angiotensin receptor blocker; $C C B=$ calcium channel blocke $; T 4=$ thyroxine. 
Figure 1: Survival benefit in months with regorafenib ${ }^{38,39,44-46}$

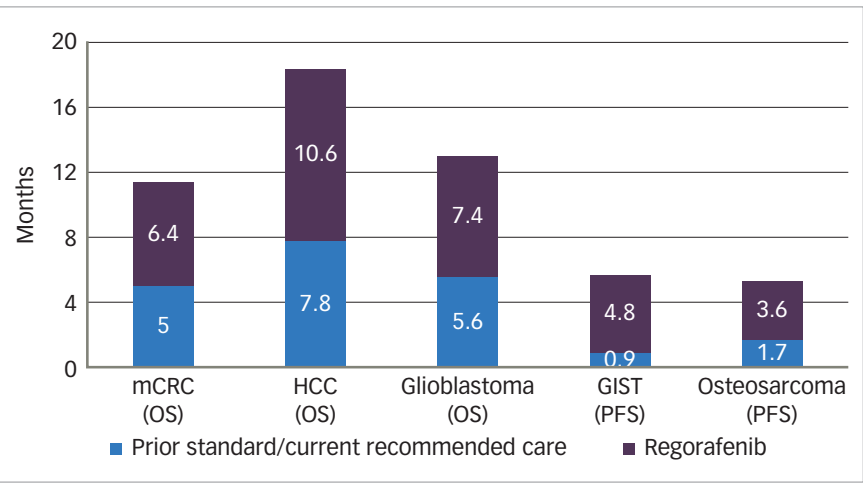

GIST = gastrointestinal stromal tumour; HCC = hepatocellular carcinoma; $m C R C=$ metastatic colorectal cancer; OS = overall survival; PFS $=$ progression-free survival.

\section{Future directions}

Five years after its approval, regorafenib remains a drug with limited clinical handling. Approved use in colorectal cancer, GIST and HCC is only for advanced metastatic disease. Combined with its high cost, there is currently little clinical benefit for patients. Moreover, distinct trials are being conducted in order to define it as a new treatment option. ${ }^{45,47,48}$ Future directions for this drug include the management of osteosarcoma. A recent placebo-controlled, double-blind trial in France has shown an increase in progression-free survival by a factor of 3 in patients with metastatic osteosarcoma who have failed every line of treatment. ${ }^{45}$ Compellingly, these new data show benefit on advanced metastatic disease as a last resort, similarly to all current approved uses.

Recent data suggest a possible synergic effect between regorafenib and immune checkpoint inhibitors, as has been shown in the REGONIVO trial. ${ }^{47}$ This phase $\mathrm{Ib}$ trial comparing regorafenib and its combination with nivolumab in patients with advanced gastric cancer or colorectal cancer, demonstrated $38 \%$ objective response rate $(44 \%$ in gastric cancer and $36 \%$ in colorectal cancer) and a tolerable side effects profile in the combination group. This intriguing benefit may be due to reduction of tumour-associated macrophages by regorafenib, increasing the tumour's sensitivity to nivolumab. Currently, the REGONIVO phase II trial is under way and could soon corroborate this hypothesis (ClinicalTrials.gov identifier: NCT04030260). Additionally, a latter phase II clinical trial has demonstrated that regorafenib is superior to lomustine in advanced and relapsed glioblastoma. ${ }^{48}$ The REGOMA trial, in Italy, has indicated a significant improvement in overall survival (hazard ratio 0.50; 95\% confidence interval 0.33-0.75; log-rank $p=0.0009$ ) as compared with lomustine therapy. ${ }^{48}$

The REVERCE studies have been conducted with regorafenib and cetuximab in the treatment of metastatic colorectal cancer. The results obtained on the sequence of the use of such drugs in the treatment of this cancer suggest that the ideal order would be the initial administration of regorafenib followed by cetuximab, which is different from the standard protocol currently used. The results showed improved overall survival of the patients and the benefit seemed to be driven mostly by greater activity of cetuximab than regorafenib as the second treatment. 49,50

The INTEGRATE trial of regorafenib monotherapy in gastric cancer showed that this drug was well tolerated and that there was no damage in patients' quality of life compared with those who received placebo and that it did not appear to have an excessively negative effect on those parameters from toxicity. ${ }^{51,52}$ Research projects highlighted that baseline levels of pain, appetite, constipation and physical functioning were found to be significant prognostic factors for survival. ${ }^{53}$ Also, this trial demonstrated that regorafenib had considerable activity in the primary progression-free survival endpoint. ${ }^{54,55}$ Additionally, the phase II ReDOS trial was performed from 2015-2018 and the authors showed that a dose-escalation strategy for regorafenib is an achievable alternative to the standard regorafenib dosing strategy of $160 \mathrm{mg} /$ day, especially in patients with metastatic colorectal cancer. It was also found that patients treated with dose escalation had a higher frequency of post-progression treatment and numerically longer overall survival. .4,55 $^{5}$

Regarding tolerability of regorafenib when employed to treat colorectal cancer, limited data are available on the tolerance in the older patient population, and the decision must be made considering the minimal survival benefit and the toxicity profile. ${ }^{56}$ Considering this drug in HCC treatment, research projects emphasise that there is an acceptable tolerance profile and that regorafenib provides a survival benefit. ${ }^{57}$ For GIST treatment, several authors state that regorafenib is well tolerated, with no unexpected toxicities. 58,59

Further research is needed to determine which patients can benefitthe most from this drug. As of 2019, ongoing trials are testing whether regorafenib can improve outcomes in soft tissue sarcomas, such as osteogenic sarcoma, liposarcoma, Ewing sarcoma and rhabdomyosarcoma. ${ }^{45}$

\section{Conclusion}

Despite 5 years of approval and promising pharmacodynamics, regorafenib has shown limited, yet statistically significant, benefit for various types of solid tumours. ${ }^{60}$ Labelled indications comprise colorectal cancer, GIST and HCC. Advanced phase II trials have shown significant improvements in survival for gastric cancer, glioblastoma and osteosarcoma, which may indicate future inclusion in labelled indications. ${ }^{44-47}$

Combination therapy with immune checkpoint inhibitors has been demonstrated as beneficial in phase I trials, and phase II trials are being performed. Currently, regorafenib is being investigated for other cancers as well.7,61 Many individual side effects can be used as markers for better outcomes with treatment. Among those, hand-foot syndrome and hypothyroidism are the most related to improved survival. In summary, studies have shown that regorafenib can significantly improve survival with an acceptable tolerance in a variety of solid tumours. $]$
1. Goldstein DA, Ahmad BB, Chen Q, et al. Cost-effectiveness analysis of regorafenib for metastatic colorectal cancer J Clin Oncol. 2015;33:3727-32

2. Wilhelm SM, Dumas J, Adnane L, et al. Regorafenib (BAY 73-4506): a new oral multikinase inhibitor of angiogenic, stroma and oncogenic receptor tyrosine kinases with potent preclinica antitumor activity. Int J Cancer. 2011;129:245-55.

3. Krishnamoorthy SK, Relias V, Sebastian S, et al. Management of regorafenib-related toxicities: a review. Ther Adv Gastroenterol. 2015;8:285-97.

4. Yoshino T, Komatsu Y, Yamada Y, et al. Randomized phase III tria of regorafenib in metastatic colorectal cancer: Analysis of the CORRECT Japanese and non-Japanese subpopulations. Invest
New Drugs. 2015;33:740-50

Adenis A, de la Fouchardiere C, Paule B, et al. Survival, safety, and prognostic factors for outcome with Regorafenib in patients with metastatic colorectal cancer refractory to standard therapies: Results from a multicenter study (REBACCA) nested within a compassionate use program. BMC Cancer. 2016;16:518.

6. Thangaraju $P$, Singh $H$, Chakrabarti A. Regorafenib: a novel tyrosine kinase inhibitor: a brief review of its therapeutic potential in the treatment of metastatic coloraculic and advanced gastrointestinal stromal tumors Indian J cancer. and advanced gastrointestinal stromal tumors. Indian J Cance
2015;52:257-60. 7. Joerger M, Güller U, Bastian S, et al. Prolonged tumor response associated with sequential immune checkpoint inhibito combination treatment and regorafenib in a patient with advanced pretreated hepatocellular carcinoma. J Gastrointest Oncol. 2019;10:373-8.

8. Grünewald FS, Prota AE, Giese A, Ballmer-Hofer K. Structure-function analysis of VEGF receptor activation and the role of coreceptors in angiogenic signaling. Biochim Biophys Acta Proteins Proteomics. 2010:1804:567-80.

9. Brozzo MS, Bjelić S, Kisko K, et al. Thermodynamic and structural description of allosterically regulated VEGER-2 dimerization. Blood. 2012;119:1781-8.

10. Nakamura Y, Furukawa Y, Hamamoto R, Nakatsuru S. Methods of identifying agents that modulate methylation of VEGFR1 
by SMYD3. US patent 8,354,223B2. 15 Jan 2013. Available at: https://patentimages.storage.googleapis.com/6f/83/6d/ dfod8b037e9a38/US8354223.pdf (accessed 21 January 2020).

11. Shinkai $A$, Ito $M$, Anazawa $H$, et al. Mapping of the sites involved in ligand association and dissociation at the extracellular domain of the kinase insert domain-containing receptor for vascular endothelial growth factor. J Biol Chem. receptor for vascular

12. Fuh $G, L i B$, Crowley $C$, et al. Requirements for binding and signaling of the kinase domain receptor for vascular endothelia growth factor. J Biol Chem. 1998;273:11197-204.

13. Schlessinger J. Signal transduction: Autoinhibition control. science. 2003;300:750-2.

14. Eriksson A, Cao R, Roy J, et al. Small GTP-binding protein Rac is an essential mediator of vascular endothelial growth factor-induced endothelial fenestrations and vascular permeability. Circulation. 2003;107:1532-8.

15. Yang $Y, X i e P$, Opatowsky $Y$, Schlessinger J. Direct contacts between extracellular membrane-proximal domains are required for VEGF receptor activation and cell signaling. required for VEGF receptor activation and cell

16. Sanz-Garcia E, Argiles G, Elez E, Tabernero J. BRAF mutant colorectal cancer: Prognosis, treatment, and new perspectives. Ann Oncol. 2017;28:2648-57.

17. Carmeliet $P$, Collen D. Vascular development and disorders: Molecular analysis and pathogenic insights. Kidney Int 1998;53:1519-49.

18. Alitalo K, Koivunen E, Kubo H. VEGFR-3 inhibitor materials and methods. US patent 7,611,711B2. 3 Nov 2009. Available at: www.freepatentsonline.com/7611711.pdf (accessed 21 January 2020).

19. Robinson CJ, Stringer SE. The splice variants of vascular endothelial growth factor (VEGF) and their receptors. J Cell SCi. 2001;114:853-65.

20. Ascierto PA, Kirkwood JM, Grob JJ, et al. The role of BRAF V600 mutation in melanoma. J Trans/ Med. 2012;10:85.

21. Margolis B, Skolnik EY. Activation of Ras by receptor tyrosine kinases. J Am Soc Nephrol. 1994:5:1288-99.

22. Emuss V , Marais, R. The biology and oncology of RAF-ERK signaling. In: Neidle S, Cancer drug design and discovery. Amsterdam: Elsevier, 2007;382

23. Peters KG, Marie J, Wilson E, et al. Point mutation of an FGF receptor abolishes phosphatidylinositol turnover and Ca2+ flux but not mitogenesis. Nature. 1992;358:678-81.

24. Mohammadi M, Dionne CA, Li W, et al. Point mutation in FGF receptor eliminates phosphatidylinositol hydrolysis without affecting mitogenesis. Nature. 1992;358:681-4.

25. Wellbrock $C$, Karasarides M, Marais R. The RAF proteins take centre stage. Nat Rev Mol Cell Biol. 2004;5:875-85.

26. Niault TS, Baccarini M. Targets of Raf in tumorigenesis. Carcinogenesis. 2010:31:1165-74.

27. Emuss V, Garnett M, Mason C, Marais R. Mutations of C-RAF are rare in human cancer because C-RAF has a low basal kinase activity compared with B-RAF. Cancer Res. 2005,65.9719-26.

28. Pritchard CA, Samuels ML, Bosch E, Mcmahon M. Conditionally oncogenic forms of the A-Raf and B-Raf protein kinases display different biological and biochemical properties in NIH 3 T3 cells. Mol Cell Biol. 1995;15:6430-42.

29. Davies H, Bignell GR, Cox C, et al. Mutations of the BRAF gene in human cancer. Nature. 2002;417:949-54.

30. Garnett MJ, Rana S, Paterson H, et al. Wild-type and mutant B-RAF activate C-RAF through distinct mechanisms involving heterodimerization. Mol Cell. 2005:20:963-9.

31. Rushworth $L K$, Hindley $A D$, O'Neill E, Kolch W. Regulation and role of Raf-1/B-Raf heterodimerization. Mol Cell Biol. 2006;26:2262-72.

32. Rajakulendran T, Sahmi M, Lefrançois M, et al. A dimerization-dependent mechanism drives RAF catalytic activation. Nature. 2009;461:542-5

33. Weber CK, Slupsky JR, Andreas Kalmes H, Rapp UR. Active Ras induces heterodimerization of CRaf and BRaf. Cancer Res. 2001;61:3595-8.

34. Ritt DA, Monson DM, Specht SI, Morrison DK. Impact of feedback phosphorylation and Raf heterodimerization on normal and mutant B-Raf signaling. Mol Cell BiO 2010;30:806-19.

35. Pratilas CA, Taylor BS, Ye Q, et al. V600EBRAF is associated with disabled feedback inhibition of RAF-MEK signaling and elevated disabled feedback inhibition of RAF-MEK signaling and elevate
transcriptional output of the pathway. Proc Natl Acad SCi USA. 2009:106:4519-24

36. Yoshino K, Manaka D, Kudo R, et al. Metastatic colorectal cancer responsive to regorafenib for 2 years: a case report. J Med Case Rep. 2017;11:227.

37. Bekaii-Saab TS, Ou FS, Anderson DM, et al. Regorafenib dose optimization study (ReDOS): Randomized phase II tria to evaluate dosing strategies for regorafenib in refractory metastatic colorectal cancer. An ACCRU Network study. J Clin Oncol. 2018;36(Suppl. 4):611.

38. Demetri GD, Reichardt P, Kang YK, et al. Efficacy and safety of regorafenib for advanced gastrointestinal stromal tumours after failure of imatinib and sunitinib (GRID): An internationa multicentre, randomised, placebo-controlled, phase 3 trial. Lancet 2013:381:295-302.

39. Bruix J, Qin S, Merle P, et al. Regorafenib for patients with hepatocellular carcinoma who progressed on sorafenib treatment (RESORCE): a randomised, double-blind, tracebo-controlled, phase 3 trial Lancet. 2017:389:56-66.

40. Kim JH, Kim SY, Kim KP, et al. Regorafenib-induced hypothyroidism as a predictive marker for improved survival in metastatic or unresectable colorectal cancer refractory to standard therapies: a prospective single-center study. Targeted Oncol. 2019;14:689-97.

41. Schirripa M, Pasqualetti G, Giampieri R, et al. Prognostic value of thyroid hormone ratios in patients with advanced metastatic colorectal cancer treated with regorafenib: the TOREADOR study. Clin Colorectal Cancer. 2018;17:e601-15.

42. Giampieri R, Prete MD, Prochilo T et al. Off-target effects and clinical outcome in metastatic colorectal cancer patients receiving regorafenib: the TRIBUTE analysis. Sci Rep. 2017;7:45703.

43. Bekaii-Saab T. A closer look at regorafenib. Clin Adv Hematol Oncol. 2018:16:667-9.

44. Ferraro D, Zalcberg J. Regorafenib in gastrointestinal stroma tumors: clinical evidence and place in therapy. Ther Adv Med Oncol. 2014;6:222-8.

45. Duffaud F, Mir O, Boudou-Rouquette P, et al. Efficacy and safety of regorafenib in adult patients with metastatic osteosarcoma: a non-comparative, randomised, double-blind, placebo-controlled, phase 2 study Lancet Oncol. 2019:20:120-33.

46. Attia S, Bolejack V, Ganjoo KN, et al. A phase II trial of regorafenib (REGO) in patients (pts) with advanced Ewing SARCO24 triat resuls. SARC024 trial results.J Clin Oncol. 2017;35(Suppl. 15):11005.

7. Fukuoka S, Hara H, Takahashi N, et al. Regorafenib plus nivolumab in patients with advanced gastric (GC) or colorectal cancer (CRC): An open-label, dose-finding, and dose-expansion phase 1b trial (REGONIVO, EPOC1603). J Clin Oncol. 2019; 2020;38:2053-6

48. Lombardi G, De Salvo GL, Brandes AA, et al. Regorafenib compared with lomustine in patients with relapsed glioblastoma (REGOMA): a multicentre, open-label, randomised controlled, phase 2 trial. Lancet Oncol. 2019;20:110-9.

49. Shitara $\mathrm{K}$, Yamanaka T, Denda T, et al. REVERCE: a randomized phase II study of regorafenib followed by cetuximab versus the everse sequence for previously treated metas

50. Killock D. mCRC: sequencing in REVERCE. Nat Rev Clin Oncol. 2019;16:67.

51. Itchins $\mathrm{M}$, Pavlakis $\mathrm{N}$. The evolving landscape of treatment for advanced gastric cancer and the role of anti-angiogenic therapy: Implications from results of the INTEGRATE study. Transl Gastroenterol Hepatol. 2017:2:29.

52. Martin AJ, Gibbs E, Sjoquist K, et al. Health-related quality of life associated with regorafenib treatment in refractory advanced gastric adenocarcinoma. Gastric Cancer. 2018;21:473-80

53. Pavlakis N, Sjoquist KM, Martin AJ, et al. Regorafenib for the treatment of advanced gastric cancer (INTEGRATE): a multinational placebo-controlled phase II trial. J Clin Oncol. 2016;34:2728-35.

54. Bekaii-Saab TS, Ou FS, Ahn DH, et al. Regorafenib dose-optimisation in patients with refractory metastatic colorectal cancer (ReDOS): a randomised, multicentre, colorectal cancer (ReDOS): a randomised, multicentre,

55. Hofheinz RD, Stintzing S. Study evidence confirms current clinical practice in refractory metastatic colorectal cancer. the ReDOS trial. Lancet Oncol. 2019;20:1036-7.

56. Hubbard JM. Management of colorectal cancer in older adults. Clin Geriatr Med. 2016;32:97-111.

57. Heo YA, Syed YY. Regorafenib: a review in hepatocellular carcinoma. Drugs. 2018;78:951-8.

58. Rey JB, Launay-Vacher V, Tournigand C. Regorafenib as a single-agent in the treatment of patients with gastrointestina tumors: an overview for pharmacists. Targeted Oncol. 2015;10:199-213.

59. Weekes C, Lockhart AC, Lee JJ, et al. A phase 1b study evaluating the safety and pharmacokinetics of regorafenib in combination with cetuximab in patients with advanced solid tumors Int J Cancer. 2019:145:2450-8.

60. $Y$ in $X$, Yin $Y$, Shen $C$, Chen $H$, Wang J, Cai Z, et al. Adverse events risk associated with regorafenib in the treatment of advanced solid tumors: meta-analysis of randomized controlled trials. Onco Targets Ther. 2018;11:6405-14.

61. Fondevila F, Méndez-Blanco C, Fernández-Palanca P, González-Gallego J, Mauriz JL. Anti-tumoral activity of single and combined regorafenib treatments in preclinical models of liver and gastrointestinal cancers. Exp Mol Med. 2019;51:109. 